\title{
Algunos aspectos de la proclamación de la República en Melilla: Abril Elecciones Municipales, 1931
}

Antonio Bravo Nieto

Antecedentes

Cuando en enero de 1930, dimite Primo de Rivera, deja al país en una situación más que precaria, y a la configuración del estado en un difícil trance, de salidas poco previsibles. No hay que olvidar que su ascenso al poder constituyó la ruptura con la legitimidad constitucional, y en este sentido el asentimiento del monarca, Alfonso XIII, fue manifiesto.

La caída de Primo de Rivera es atribuida a una circular que envió a los Capitanes Generales para que se pronunciasen sobre la conveniencia o inconveniencia de continuar con su gestión, y cuya respuesta no fue satisfactoria.

Hay que apuntar por encima de este dato, que la situación económica y social había empeorado visiblemente en el país y que la coyuntura internacional no era la más propicia para una recuperación global. Al perder parte de los apoyos tanto políticos como sociales en los que basó su actuación en una primera época, su continuidad al frente del gobierno se hizo insostenible.

Primo de Rivera intentó la anulación de las luchas políticas en varios niveles: municipal, provincial y nacional, desmontando los cauces representativos del país. Comenzó una institucionalización, que no tuvo éxito, al crear el partido Unión Patriótica.

El fracaso de este proceso fue notorio. Las fuerzas políticas tradicionales se hallaban divididas y muy mermada su credibilidad. Dos nuevas tendencias generales, republicanos y socialistas, empezaban a contar con un apoyo popular fundamental.

Pero antes de pasar a ver los partidos y su situación en este contexto particular, veamos cual era la coyuntura donde se habian desarrollado las fuerzas políticas tradicionales, que por otra parte marcaba terminantemente sus rasgos básicos. Me refiero al caciquismo.

El mecanismo de éste, consistía básicamente en que el gobierno designa- 
ba a los gobernadores provinciales, escogiendo estos a sus "caciques" 0 agentes locales; que a cambio de disponer de la influencia política en su distrito aseguraban el voto para el candidato del partido.

Como consecuencia, se daba una secuela de corrupción política que solo fue posible por unos factores históricos determinados: la apatia e indiferencia política por un lado y el escepticismo de la clase gobernante por otro.

Fruto de una época determinada, se resquebrajó cuando en las ciudades, los electores comenzaron a organizarse, rompiendo el dominio de los manipuladores electorales.

El resultado del sistema fue la ineficacia municipal. Quienes deseaban reformar la vida política, pasaban inexorablemente por conceder a los municipios una mayor área de actuación.

Como Raymond Carr señala, "el término caciquismo es uno de esos pocos descubrimientos terminológicos que condenan a todo un régimen: concentraba la crítica en uno de los mecanismos inferiores de la política, la falsificación de las elecciones y el sistema de influencias que hacía posible el fraude" (1).

El turno pacífico, roto por Primo de Rivera, se fundaba en esta base política. Pero la España de 1930 y 1931 había cambiado, tanto social como polfticamente. Estos presupuestos que fueron posibles para una época determinada no lo serán para el momento.

Con el nombramiento del General Berenguer, Alfonso XIII, quiere volver a la normalidad constitucional, restableciendo la del 1876, aunque esto no lo consiguiera totalmente, y por otra parte recuperar algunas de sus prerogativas perdidas en 1923.

Berenguer intentó por todos los medios eliminar la fórmula de Cortes Constituyentes, por las responsabilidades que se le pudieran plantear al rey.

Mientras tanto, los partidos tradicionales siguieron enzarzados en una dialéctica impropia de un momento al que se le pudiera calificar de prerevolucionario.

Así la convocatoria de elecciones para noviembre de 1930, fracasó ante la negativa de participar en ellas de republicanos, socialistas e incluso de algunos monárquicos.

De este modo se va conformando una corriente revolucionaria que va a prescindir de cualquier planteamiento continuista y que ve en la forma de gobierno un obstáculo insalvable para la vida política nacional. cales.

El año 1930, fue de afianzamiento de las organizaciones políticas y sindi-

Con anterioridad, en 1926, un pacto republicano había cuajado en una formación llamada Alianza Republicana. En 1929 aparecía el Partido Radical Socialista.

(1) España 1808-1939. Raymond Carr. Ariel, 1979. 
Como señala Tuñón de Lara "las fuerzas republicanas se organizaron rápidamente por todo el país y adquirieron gran importancia entre las clases medias" (2).

Los socialistas habían ido creciendo paulatinamente, adquiriendo experiencia de organización desde que participara la U. G. T., en la estructura corporativa del Directorio.

Los republicanos se comprometieron en el Pacto de San Sebastián con la izquierda catalana, y la adhesión de los socialistas, a una acción conjunta que llevará hacia la eliminación de la monarquía y la instauración de una república.

La rebelión programada para el 15 de diciembre de 1930, es adelantada al día 12 en Jaca por los militares Galán y Hernández; su fracaso y "martirio" hizo posible un viraje de la opinión contra la monarquía, que ya contaba con la oposición de intelectuales como Marañón, Ortega y Gasset o Pérez de Ayala.

Dimitido Berenguer, se encarga al almirante Aznar en febrero de formar gobierno, intentando una operación de más envergadura, con convocatoria de elecciones municipales para abril y generales en mayo. Pensaba ganar popularidad, pero la opinión era inquebrantable. Así, el Comité Revolucionario, encarcelado tras los sucesos de Jaca, contaba con un fuerte apoyo popular, e incluso moral, lo que era un gran indicativo de por donde iba la opinión política del momento. La conjunción republicano-socialista desplegaba una actividad sin precedentes. La gente acudía en masa a los mítines, y veía en la futura república un ideal abstracto que colmase las más dispares aspiraciones.

No obstante, la coalición anti-monárquica no podía tener una conciencia absoluta sobre la impopularidad de Alfonso XIII y sobre su posible triunfo en las urnas. Esta es la causa de que previamente las fuerzas coaligadas tacharan a las elecciones de abril de insinceras, para en su caso, proclamar la república mediante un golpe de fuerza, si los resultados eran adversos.

No obstante hay que advertir que estas elecciones eran las primeras que se celebraban con una certeza bastante alta de que no iban a ser falseadas o manipuladas de uno $u$ otro modo, y a la larga los hechos fueron un buen exponente de esta afirmación.

Celebrados los comicios, al atardecer del 12 de abril se empezaron a conocer los resultados en capitales. La conjunción habia ganado en casi todas las ciudades pero no en las zonas rurales. El peso específico de las primeras llevó a una sobrevaloración de los resultados.

Las clases conservadoras perdieron la confianza en la monarquía como baluarte contra la revolución social.

Las municipales fueron transformadas en un plebiscito en contra de la monarquía.

(2) La España del siglo XX. M. Tữón de Lara. Laia, 1977. 
La historiografía no se pone de acuerdo en cuanto a los resultados electorales (Sevilla Andres, Martínez Cuadrado, Artola, Javier Tusell, ...), pero si coinciden en las importantes consecuencias.

Algunos ministros, Bugallal y de la Cierva, aconsejaron al monarca instaurar una dictadura; otros, como Romanones, un acuerdo con el Comité Revolucionario para formar gobierno de coalición que convocase Cortes constituyentes, pero dicho comité se negó.

Así el día 15 de abril, Alfonso XIII, sale de España al exilio quedando proclamada la República.

Para Artola la decisión del monarca es lógica, pues si en las municipales las capitales designaban un 2,1 por 100 de los concejales a elegir, en las generales a celebrar en mayo, la proporción era de un 28 por 100 de diputados del total.

Quedaba formado un gobierno de Concentración Nacional compuesto por los siguientes partidos: Derecha Liberal Republicana (2), Partido Radical (2), Partido Radical Socialista (2), Socialista (3), Acción Republicana (1), Esquerra Republicana (1), ORGA, galleguista (1).

\section{VISION GENERAL EN MELILLA}

Los hechos que se van a desarrollar en la ciudad de Melilla y que van a conducir a la proclamación de la II República vienen dados por dos planos o coordenadas.

El primero y más importante será el acontecer paralelo en el resto del país, marcado a su vez por situaciones de tipo político, económico y social. Este plano, actuará a modo de "tirón" de los acontecimientos de la ciudad, que no podrían explicarse de otro modo.

En segundo lugar, la propia singularidad de la Plaza va a aportar unos rasgos particulares que la diferenciarán de otras ciudades.

Pero hay que señalar que los melillenses participaban en 1931, de los mismos deseos, problemas y aspiraciones políticas, que el resto de los españoles. La singularidad que veíamos, se reflejará en cuanto se afronte, o solucionen problemas estrictamente locales, que, insisto, por otra parte van inmersos en el devenir nacional.

En la ciudad de Melilla, esta época representa la normalización del municipio con respecto al conjunto nacional, y su afianzamiento institucional.

Este factor llevará por primera vez en su historia, a un ayuntamiento elegido por votación popular, y posteriormente a su primer diputado a Cortes (en el mismo 1931) lo que llevaba pidiendo desde 1914. También se tiende a deslindar Ceuta y Melilla totalmente del Protectorado en múltiples sectores, del que es más interesante el político, aunque no se pueda separar este aspecto de la profunda crisis económica.

En este sentido se puede afirmar que será este primer gobierno de la Re- 
pública el que lleve a Ceuta y Melilla a una mayor equidad con el resto peninsular.

En cuanto a los factores económicos, se alcanzan cotas de crisis muy elevadas, lo que será decisivo para la creación de un ambiente social tenso, al que la Junta Municipal intentará poner solución mediante una beneficencia hipertrofiada. Esto incidirá en gran modo sobre el problema del paro y sindical.

La sociedad, no deja de ser un tema interesante por que en estas fechas la ciudad presenta aún grandes sectores, emigrantes, que no han perdido todavía su identidad de origen, lo que estratifica en cierto modo la población por procedencia.

Dentro de esta compleja sociedad los grupos militares y hebreo, son de gran interés por su actuación en los acontecimientos políticos.

La diversificación de la vida y de los acontecimientos de la ciudad no pueden desdeñar ninguno de estos factores.

La actividad de los partidos políticos y el análisis electoral revestirá gran importancia por cuanto indican como influyen las anteriores circunstancias en el sentir político, primando en las municipales de abril de 1931, los grupos republicanos (3).

Se comprueba por otra parte como el desfase de fecha que se produce en las elecciones municipales de Melilla provoca un retraimiento del voto monárquico, al estar ya de hecho proclamada la II República cuando se efectúan los comicios en la ciudad.

Los partidos políticos dan muestra de su poca consistencia, y lo apresurado de su conformación, con la entrada (junto a militantes convencidos y antiguos) de personas unidas a estos circunstancialmente, que demostrarán en más de una ocasión su inexperiencia y la poca solidez de su ideología (trasiego político entre partidos y reajuste en estos, constatado ya en mayo de 1931).

Por otro lado la misma opinión pública no estaba totalmente formada y habrá cambios repentinos en esta (3).

\section{Elecciones}

Antes de pasar al análisis de los comicios, veamos el desarrollo normativo que constituyó la base jurídica de las elecciones en Melilla.

Tras la convocatoria de elecciones municipales en España, por el gobierno Berenguer, se van ultimando los preparativos en todas partes. Así el empadronamiento general de los habitantes de España en 31 de diciembre de 1930, será el soporte demográfico sobre el que se asentarán los comicios.

(3) Poco después, a finales de mayo de 1931, en las elecciones para diputado, las preferencias bascularán hacia el partido socialista. 
En Melilla, los resultados del censo son enviados al Alto Comisario, en calidad de Gobernador Civil de las Plazas de Soberanía, el 15 de enero, existiendo en la ciudad una población de derecho y hecho de 63.169 y 59.261 pesonas respectivamente (4).

Por disposición de la Gaceta, los Ayuntamientos se reunieron el 15 de marzo para acordar el número total de concejales que debian integrar las Corporaciones a elegir.

Pero en Melilla no estaba constituido el Ayuntamiento por lo que el desarrollo electoral tendrá unas características muy peculiares. Hasta entonces regía la ciudad una Junta Municipal de carácter cívico-militar. La nueva Corporación sería el primer Ayuntamiento propiamente dicho de la Plaza.

Esta "atipicidad" creará unas normas legislativas especiales. Asi, el Subsecretario de Gobernación, dictó de forma provisional que, en Ceuta y Melilla se procediera a estas elecciones con sujeción a las mismas disposiciones que al resto de España (5).

La Sesión del Pleno de la Junta Municipal, hace efectivo un acuerdo de fecha 27 de junio de 1930, dividiendo en ocho distritos la ciudad, con un total de 11.140 votantes que elegirían 37 concejales a un coeficiente de 301 electores por concejal (6).

Nuevas normas aportará el Consejo de Ministros al decretar que la proclamación de candidatos en Melilla se realice utilizando la forma de propuesta por los electores, mediante elección directa, siendo candidatos los que obtengan un 20 por 100 de la antevotación (7).

Pero ya en el mismo día 25 el ministro de la Gobernación declara sus intenciones de proponer al Consejo de Ministros que no se aplicara en Melilla el aspecto de la Ley que se refería a la proclamación de candidatos, aduciendo tratarse de la primera vez que se procedía a elegir Ayuntamiento. Esta propuesta será acordada por el Consejo de Ministros y el 1 de abril se recibe un telegrama del Presidente de la Junta Local del Censo Electoral de Madrid, comunicando Real Decreto de igual fecha, por el cual se aplazan las elecciones municipales por ocho días en Melilla, suspendiendo la antevotación de candidatos (8).

Estas medidas suponen un retraso de la ciudad con el resto del país y van a marcar el desarrollo y resultado electoral definitivamente.

$\mathrm{La}$ antevotación se realiza el día 9 de abril; se formaron tantas listas como candidatos y cada elector pudo proponer oralmente uno menos del número de los que había que elegir.

(4) Boletin Oficial de la Junta Municipal de Melilla, 15 de enero de 1931.

(5) El Telegrama del Rif., núm. 10.935, de 17 de marzo de 1931. Melilla.

(6) Acta Muricípal de 15 de marzo de 1931, págs. 18 y 19. Melilla.

(7) El Telegrama del Rif., núm. 10.946 de 25 de marzo de 1931 . Mebilla.

(8) El Telegrama del Rif., núm. 10.953 de 2 de abril de 1931. Melilla. 
El desarrollo de estas antevotaciones fue normal en conjunto. Los incidentes principales se basaron en supuesta coacciones, suplantación de votos $y$ un incidente en el puerto entre grupos de ambos bandos. También se contrataron taxis para llevar a los votantes a las mesas.

Algunos independientes se retiraron por el bajo número de votos obtenidos (9), habiendo en todos los distritos propuestos (excepto en el 8. ) más candidatos que concejales asignados.

El día 12 se constituye la Junta Local del Censo Electoral, y con la asistencia de candidatos de la izquierda, del Grupo Africanista y obreros se proclaman los candidatos.

La Junta, según el art. 29 de la Ley Electoral (10), nombra a cinco concejales definitivamente, los señores Orte, García Viñas, Mendizabal, Comes y Palacios, protestando los cuatro primeros (republicanos y socialistas) de los beneficios del amparo del citado art. 29 (11).

Más adelante analizaremos los resuitados de esta antevotación, en comparación con las elecciones municipales del día 19.

Reseñaremos que en la ciudad se presagiaba el triunfo de las izquierdas (ver retirada de los Africanistas) como bastante seguro, lo que determinaría el desarrollo inmediato de los comicios.

En este sentido el Delegado Gubernativo, señor Solans, dictó un bando el 8 de abril, en el que se pedía serenidad a los electores y "para que en ningún momento antepongan sus entusiasmos e ideales políticos..., al supremo amor a la Patria" (12).

Por otra parte se acusó a la Junta Municipal de tener responsabilidades en el retraso electoral, lo que esta negaria terminantemente.

También se le acusa de apoyar veladamente al grupo Africanista, lo que es cierto en parte, ya que el Telegrama del Rif mantenía una línea cercana a este grupo, y el director de este era el mismísimo presidente de la Junta Municipal, señor Cándido Lobera.

Mientras tanto en el resto del país se procedía, el día 12, a elegir a los nuevos Ayuntamientos, y poco a poco se fue configurando el triunfo de los partidos de oposición a la Monarquía. Los comicios municipales se habían transformado en Referéndum.

Por tanto, ya había sido proclamada la República Española cuando se procede a efectuar las elecciones en Melilla. El ambiente es muy diferente

(9) El Telegrama del Rif., núm. 10.960 de 10 de abril de 1931. Melilla.

(10) El Telegrama del Rif., núm. 10.960 de 10 de abril de 1931. Melilla.

(11) Aranzadi. Nuevo Diccionario de Legislación. Tomo VII. Pamplona, 1976, pág. 10.003. 'En los distritos donde no resulten proclamados candidatos en mavor número de los llamados a ser elegidos, la proclamación de candidatos equivale a su elección y les releva de la necesidad de someterse a ella". Ley Electoral de 8 de agosto de 1907.

(12) El Telegrama del Rif., núm. 10.962 de 12 de abril de 1931. Melilla. 
pues, al del resto de la nación: por un lado ya se conocía el desarrollo de los acontecimientos políticos y por otro, supone (como veremos), un retraimiento electoral de los grupos monárquicos. En este sentido las elecciones estaban ya ganadas por las izquierdas de antemano, aunque hay que señalar muchos matices y diferencias significativas por distritos.

Así la consulta electoral se celebró el día 19 de abril, de 7 a 20 horas, siendo cerrados los colegios al público a las 16 horas.

La votación fue secreta, de uno en uno, en las que depositarían la papeleta con los concejales elegidos. La edad para votar se situaba en los 25 años, y era un voto exclusivamente masculino, de acuerdo con la Ley Electoral citada.

Antes de pasar a analizar los resultados, veamos unos datos sobre los grupos sociales que integraban las 11.140 personas con derecho a voto:

\begin{tabular}{|c|c|c|}
\hline & por 100 & por 100 \\
\hline 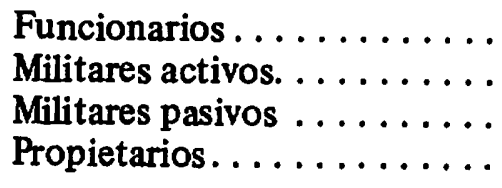 & $\begin{array}{l}0,87 \\
9,88 \\
0,56 \\
0,37\end{array}$ & 11,68 \\
\hline $\begin{array}{l}\text { Prof. Liberales. } \ldots \ldots \ldots \ldots \\
\text { Empleados. . . . . } \ldots \ldots \ldots \ldots \\
\text { Comerciantes. . } \ldots \ldots \ldots \ldots\end{array}$ & $\begin{array}{r}13,76 \\
7,61 \\
7,54\end{array}$ & 28,91 \\
\hline $\begin{array}{l}\text { Obreros................. } \\
\text { Sin profesión. . . . } \ldots \ldots \ldots\end{array}$ & $\begin{array}{r}55,50 \\
4,48\end{array}$ & 59,98 \\
\hline
\end{tabular}

Destaca casi una décima parte de militares y funcionarios, un tercio entre profesiones liberales, empleados y comerciantes y casi un 60 por $100 \mathrm{de}$ obreros. Estas diferencias marcaron férreamente las ideologías políticas.

Los grupos primarios votaron en su mayoría por las izquierdas, azuzados por la gravísima crisis económica que les azotaba.

Comerciantes y profesionales liberales, estaban influenciados por las ideas republicanas que habrian ido calando en estos grupos desde la venida a Melilla de gentes de Levante y Cataluña a partir de 1909, trayendo esta ideología.

El grupo militar se mantuvo al principio ajeno a confrontaciones directas, pero salvo personalidades aisladas y significativas (Miaja) primaron las ideas monárquicas en las votaciones.

Pasemos a continuación a desglosar los resultados por distritos, comparándolos con los de la antevotación. 


\section{Distrito $1 .^{0}$}

Corresponde a los barrios de Medina Sidonia, Estopiñán y Ataque Seco. El número de personas con derecho a voto es de 1.009 , que eligen tres concejales.

Por profesiones destacaremos los siguientes grupos:

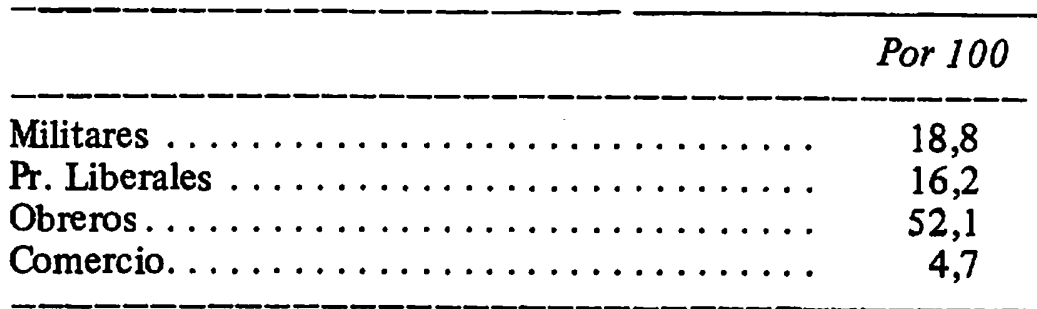

Es significativo el alto número de militares, casi un quinto del total, y de las profesiones liberales. El analfabetismo supone un tercio del total. Comparando estos resultados de la antevotación y comicios, vemos como se produce una brusca caída de Jacob Salama y Juan Muñoz Orozco, posiblemente a causa de la inhibición señalada, debida al desánimo que cundió entre los monárquicos al conocer la proclamación republicana.

Salen elegidos: (13.)

\begin{tabular}{|c|c|c|c|}
\hline & & votos & por 100 \\
\hline $\begin{array}{l}\text { Aurelio Solis Díaz } \\
\text { Gaspar García Dómine } \\
\text { José Mingorance Alons }\end{array}$ & $\begin{array}{l}\text { (Republicano) } \\
\text { (Socialista) } \\
\text { o(Independiente) }\end{array}$ & $\begin{array}{r}511 \\
508 \\
30\end{array}$ & $\begin{array}{r}50,6 \\
50,3 \\
2,9\end{array}$ \\
\hline
\end{tabular}

Supuso pues igualación entre republicanos y socialistas, y la figura de Mingorance como independiente de izquierdas.

(13) Según la Ley Electoral cada votante podía designar más de un candidato. Por eso, el tanto por ciento señalado para cada concejal, viene dado por el número de votos que recibió por cada distrito, en relación con el número total de personas con derecho a ejercer el sufragio en dicha demarcación. 


\section{Distrito 2.0}

Corresponde a los barrios de Reina Victoria, Gómez Jordana y Príncipe de Asturias. Personas con derecho a voto 1.412, que eligen cinco concejales. Por ocupaciones destacaremos los siguientes grupos:

\begin{tabular}{|c|c|}
\hline & por 100 \\
\hline 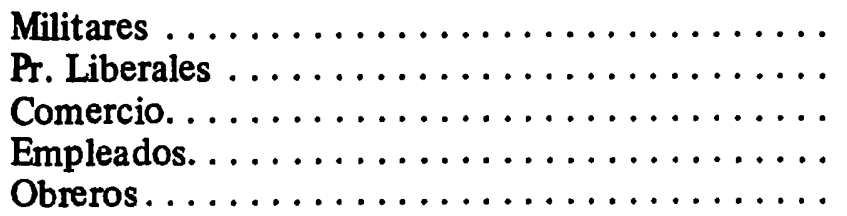 & $\begin{array}{l}24,50 \\
18,76 \\
16,43 \\
13,52 \\
18,98\end{array}$ \\
\hline
\end{tabular}

El número de ciudadanos de clase pudiente es elevadísimo, de lo que es exponente la tasa de analfabetismo, 1,5 por 100 del total.

Constituye el centro de la ciudad, donde se concentran los sectores privilegiados de Melilla. Casi una cuarta parte de militares y un quinto de población activa pertenecientes a profesiones liberales $y$ otro tanto a obreros (porcentaje mínimo).

Estos sectores marcarán las tendencias políticas; de esta forma en la antevotación, aparece Fernández de Castro en la cabecera, seguido por Fidel $\mathrm{Pi}$, ambos del grupo Africanista.

Como consecuencia de la anterioridad de la proclamación republicana a las votaciones en la ciudad, el retraimiento fue mucho mayor, $y$ estos dos candidatos, pasarán el día 19 a ocupar el cuarto y quinto puesto.

Son elegidos:

\begin{tabular}{llcc}
\hline & & votos & por 100 \\
\hline Miguel Bernardi Tevar & (republicano) & 702 & 49,7 \\
José García Viñas & (socialista) & 672 & 47,5 \\
Ricardo Fius Mollet & (republicano) & 672 & 47,5 \\
Rafael Fdez. de Castro y Pedreras & (africanista) & 168 & 11,8 \\
Fidel Pi Casas & (africanista) & 128 & 9 \\
\hline
\end{tabular}

Hay que tener en cuenta que son los únicos miembros del disuelto grupo Africanista que resultan elegidos en toda la ciudad, lo que marcaría la atipicidad de voto en este distrito por las razones reseñadas.

Por otra parte los republicanos sacan gran ventaja sobre los socialistas, al recibir presumiblemente parte del voto conservador. 


\section{Distrito 3.0}

Corresponde al barrio del Carmen. El número de personas con derecho a voto es de 1.250, que eligen cuatro concejales.

Por profesiones destacaremos:

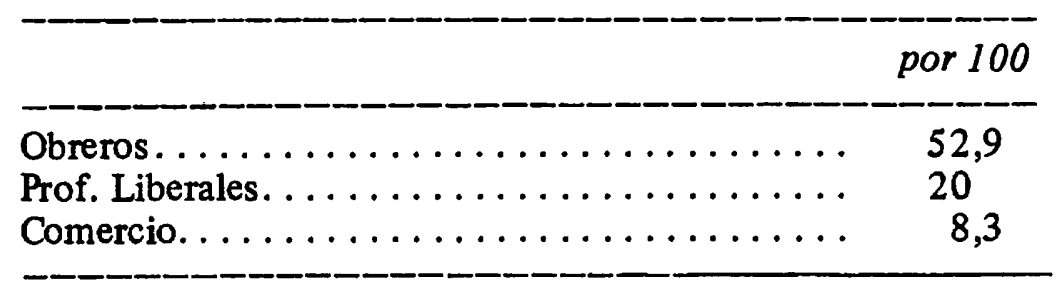

Los resultados dan como concejales a:

\begin{tabular}{llll} 
& & votos & por 100 \\
\hline Antonio García Vallejo (republicano) & 693 & 55,1 \\
Alfonso García García (socialista) & 647 & 51,5 \\
Juan Reyes Ortiz & (republicano) & 633 & 50,3 \\
José Linares Vivar & (independiente) & 189 & 15 \\
\hline
\end{tabular}

De nuevo los republicanos sacan ventaja a los socialistas, confirmando las antevotaciones, aunque se produce la caída de José Marfil y Francisco Aznar.

\section{Distrito 4.0}

Corresponde a los barrios Polígono y Hebreo. El número de ciudadanos con derecho a voto es de 1.067 , que eligen cuatro concejales.

Este distrito presenta una baj ísima proporción de militares, funcionarios, profesiones liberales, empleados y comerciantes. Destaca la gran proporción de obreros, un 72,5 por 100 .

Pero en este distrito es más interesante su procedencia racial para distinguir sus preferencias. La mayor proporción de personas hebreas va a suponer la presentación de candidatos de esta naturaleza. 
Así y confirmando los resultados de la antevotación salen elegidos:

\begin{tabular}{llcc} 
& & votos & por 100 \\
\hline Juan Espona Ristol & (republicano) & 578 & 54 \\
José Vicente López & (socialista) & 572 & 53,6 \\
Isaac Benchimol Melul & (republicano) & 510 & 47,79 \\
Jacob Salama Hassan & (independiente) & 75 & 7 \\
\hline
\end{tabular}

Hay que tener en cuenta que Isaac Benchimol y Jacob Hassan son los únicos hebreos elegidos en la ciudad. El que se hubiese elegido el distrito cuarto para su presentación supone:

- Por un lado una generación de población judia que se había integrado y participa en las inquietudes políticas y sociales del momento.

- Por otro, la presentación de un distrito "seguro", lo que implica que esta integración no había llegado a sus últimas consecuencias (14).

En las antevotaciones aparece el único musulmán de todos los distritos, Hamed Amor Zrac, con 109 votos, que pasarian en las elecciones a 16, con una brusca caída.

\section{Distrito 5.0}

Comprende los barrios de Cabrerizas Altas y Bajas, Batería Jota, Reina Regente y diseminados. Presentaba un total de 1.745 personas con derecho a voto, que eligen seis concejales.

Socialmente destacan:

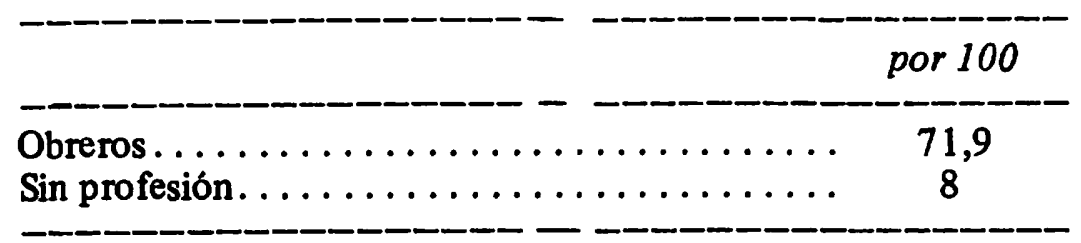

La proporción de gente llana es abultada, lo que influye en las predilecciones políticas.

(14) En la actualidad se presentan concejales hebreos que aparecen indistintamente en los diferentes partidos y son votados igualmente (ahora si) por su ideología y no por su procedencia racial. 


\begin{tabular}{llll} 
& & votos & por 100 \\
\hline Diego González Doña & (socialista) & 878 & 50,3 \\
Adolfo Hernández Quirantes & (socialista) & 866 & 49 \\
Julio Caro de Córdoba & (republicano) 877 & 50,2 \\
Francisco González García & (republicano) 869 & 49,7 \\
Felipe Aguilar Lagos & (republicano) & 35 & 2 \\
\hline
\end{tabular}
dos.

Las fuerzas entre los dos partidos aliados se encuentran muy equilibra-

No obstante con respecto a la antevotación se aprecia la desaparición casi total de Vicente Giles Fontalba (163 votos), Agustín Salomó (129 votos), José Enriquez Laguna (123 votos), y José Rubio (143 votos), que supone una tensencia conservadora-monárquica en estos.

\section{Distrito 6.0}

Comprende los barrios del General Aldave y Arizón, con 1.239 electores que designan cuatro concejales.

La proporción social de obreros supone un 52,4 por 100 .

Militares 7,1 por 100 y empleados 11,46 por 100 .

La situación social es más equilibrada, pero los resultados son casi análogos al anterior distrito:

\begin{tabular}{llll} 
& & votos & por 100 \\
\hline Eduardo Bustos González & (republicano) 630 & 50,8 \\
Juan Marcos Morales Collado & (republicano) 629 & 50,7 \\
Antonio Leiva Hidalgo & (socialista) & 610 & 49,2 \\
Miguel Gómez Morales & (republicano) & 138 & 11,9
\end{tabular}

Se vuelve a constatar inhibición de electores en la caída de candidatos como, Antonio Serrano (119 votos) y Julio Rodríguez (121 voto).

\section{Distrito 7.0}

Comprende el populoso barrio del Real, con 1.674 electores que designan cinco concejales. 
Socialmente por actividades destacan los siguientes grupos:

\begin{tabular}{|c|c|}
\hline & por 100 \\
\hline 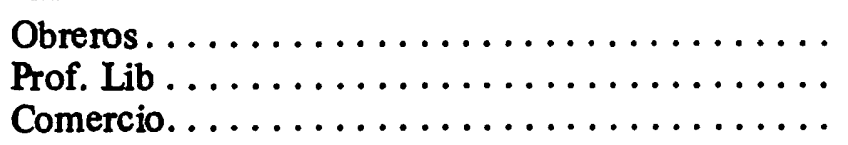 & $\begin{array}{r}70,5 \\
11,6 \\
7,8\end{array}$ \\
\hline
\end{tabular}

Militares y funcionarios presentan un indice muy bajo, es este distrito un sector obrero.

En relación con la antevotación caen estrepitosamente, Pedro Bayona, Nicolás Pérez Cerisola y Luis Weil, en el total de votos.

Con todo se confirma la cabecera:

\begin{tabular}{|c|c|c|c|}
\hline & & votos & por 100 \\
\hline $\begin{array}{l}\text { Antonio Díez Martín } \\
\text { José Pérez Pérez } \\
\text { Francisco Gómez Román } \\
\text { Luis Navarro Zapata } \\
\text { Francisco Martínez González }\end{array}$ & $\begin{array}{l}\text { (socialistas) } \\
\text { (republicano) } \\
\text { (socialista) } \\
\text { (republicano) } \\
\text { ("al servi- } \\
\text { cio de la Re- } \\
\text { pública") }\end{array}$ & $\begin{array}{l}811 \\
706 \\
638 \\
248 \\
149\end{array}$ & $\begin{array}{r}48,4 \\
42,1 \\
38,1 \\
14,8 \\
8,9\end{array}$ \\
\hline
\end{tabular}

Aunque los socialistas muestran ligera ventaja, se aprecia el equilibrio.

\section{Distrito 8.0}

Comprende los barrios Industrial, Sanjurjo, Zoco y Alfonso XIII, con un total de 1.738 personas con derecho a voto que designan seis concejales.

Se da un alto número de militares y funcionarios, 20,1 por 100 , y de profesiones liberales 14,6 por 100 . Obreros 48,7 por 100 .

En este distrito se da un hecho que va a revestir una trascendental importancia. Al no ser proclamados candidatos en mayor número de los llamados a ser elegidos, resultan designados directamente 12 concejales, sin necesidad de someterse a elección el día 19 de abril.

Así, serán estos concejales los que proclamarán la República en Melilla y constituirán una Comisión Gestora Municipal, hasta la designación del Ayuntamiento. 
Este grupo de concejales es el siguiente:

- Juan José Mendizabal Echevarría (republicano)

- Pedro Orte Velasco (socialista)

- Arquímedes Comes Carles (republicano)

- Juan Palacios Martos (independiente)

- José García Viñas (socialista)

Todos muestran descontento por esta norma, pero sólo García Viñas renuncia a su derecho, siendo elegido posteriormente en el distrito $2 .^{\circ}$ (como veíamos).

Este puesto vacante, será ocupado el día 19 de abril por Bienvenido Rutllant Carol (socialista), con un 47,52 por 100 con 826 votos.

En general, de 11.140 electores votaron 6.774 , lo que representa un 60,8 por 100 con uma abstención del 39,2 por 100 , superior al índice nacional $(32,2$ por 100$)$.

Como señalabamos este alto indice guarda proporción con el retraimiento de grupos afines a posturas monárquicas y conservadoras.

Con las dificultades que supone catalogar la filiación politica de estos primeros concejales, se pueden dar los siguientes resultados:

- Mayoría republicana con 17 concejales.

- Minoría socialista con 11 concejales.

- Grupúsculo de antiguos africanistas con 2 concejales.

- Un concejal de la asociación "Al Servicio de la República".

- Cuatro independientes, que por lo general, y a la vista de las Actas Municipales, apoyarian a unos y otros en cada caso.

El "Boom" político, hizo que en estas primeras elecciones se precipitaran muchas personas a opciones que abandonarian en el transcurso del tiempo.

De los independientes señalamos a tres de ideología conservadora como Juan Palacios, José Linares y Jacob Salama; de tendencias izquierdistas, José Mingorance.

En general los concejales pertenecen al sector terciario, destacando el número de médicos y dedicados a profesionales liberales. Eran en suma, gente conocida por el electorado.

Otros pertenecían al sector secundario, quedando descartados de estas elecciones los militares, siendo esta la primera vez que no aparecen en el gobierno municipal.

Destaca el hecho de que ninguno de ellos aparece como propietario de industrias de importancia, o gran propietario (excepto, Jacob Salama y Fidel $\mathrm{Pi}$ ), en el anuario-guía oficial de 1930 (15).

Los anteriores datos aparecen reflejados en las fuentes siguientes:

Amuario-Guta oficial de Marruecos y del Africa Española. Madrid, 1930. 
- Telegrama del Rif., núm. 10.883 de 22 de enero de 1931: Demografía comparada años 1927 a 1930.

- Telegrama del Rif., núm. 10.889 de 27 de enero de 1931: Padrón Municipal de 31 de diciembre de 1930.

- Boletín Oficial de la Junta Municipal de 15 de enero, por R. D., de 4 de marzo de 1930: Distritos, votantes, secciones, residentes, transeuntes.

- Telegrama del Rif., núm. 10.936 de 14 de abril de 1931 ; y núm. 10.967 de 21 de abril de 1931: Votos por candidatos y distritos.

- Telegrama del Rif., nú. 10.951 de 31 de marzo de 1931: censo electoral total por profesiones.

- Memoria de la Junta Municipal, 1927-1930: Censo de Población. 